Tropical Journal of Pharmaceutical Research, December 2008; 7 (4): 1179-1184

(C) Pharmacotherapy Group,

Faculty of Pharmacy, University of Benin

Benin City, 300001 Nigeria.

All rights reserved.

Research Article

Available online at http://www.tjpr.org

\title{
Quality of Artesunate Tablets Sold in Pharmacies in Kumasi, Ghana
}

\section{K Ofori-Kwakye*, Y Asantewaa and O Gaye}

Department of Pharmaceutics, Faculty of Pharmacy and Pharmaceutical Sciences, College of Health Sciences, Kwame Nkrumah University of Science and Technology, Kumasi, Ghana

\begin{abstract}
Purpose: The study was carried out to evaluate the quality of artesunate tablets sold in retail and wholesale pharmacies in Kumasi, Ghana. In particular, the study sought to ascertain the presence or otherwise of counterfeit artesunate tablets in Kumasi.

Method: Artesunate tablets were purchased from pharmacies in Kumasi for the study. The mechanical properties of the tablets were evaluated, namely: uniformity of weight, breaking strength, friability and rate of disintegration in aqueous medium. Colorimetric methods were used to determine the presence of artesunate and to assay the tablets.

Result: None of the artesunate tablets sampled was found to be a counterfeit. Most of the brands had acceptable mechanical properties in terms of mass uniformity, hardness, friability and disintegration time. However, the artesunate content of the tablets was variable (47.9-99.9\%). Six (35.3\%) of the samples passed the International Pharmacopoeia content uniformity test (93.7-99.9\%) while 11 (64.7 $\%)$ failed the test (47.9-89.4\%). However, only $3(17.6 \%)$ of the samples met the European Pharmacopoeia (Ph. Eur.) content requirements while 14 (82.4\%) failed to meet the requirements.

Conclusion: The presence of substandard artesunate tablets on the Ghanaian market should alert drug regulatory authorities to be vigilant and continually monitor the quality of this life-saving drug.
\end{abstract}

Keywords: Artesunate tablets, Artemisinins, Fast-red TR salt, Counterfeit drugs, Substandard drugs. 


\section{INTRODUCTION}

Artesunate and other artemisinin derivatives such as artemether, and dihydroartemisinin are potent drugs which are used in the management of uncomplicated malaria. Artesunate is the most widely used of the artemisinin derivatives ${ }^{1}$. The use of any of the artemisinins as monotherapy has, however, been discouraged by the WHO to minimise the development of resistance to these new antimalarials. Instead, the $\mathrm{WHO}$ has since 2001 recommended the use of artemisininbased combination therapy (ACT) as first line malaria treatment in malaria-endemic African countries. In Ghana, artesunate-amodiaquine is the ACT of choice ${ }^{2}$. The cure rate from monotherapy with artesunate and other artemisinin derivatives is low compared to the use of $\mathrm{ACT}^{3}$. In spite of the recommendation from the $\mathrm{WHO}$, monotherapy with artesunate tablets is commonly employed in the management of malaria in Ghana and many other countries in Africa ${ }^{4,5}$.

Whether employed as monotherapy or as a component of ACT, artesunate plays a pivotal role in the global fight against malaria, hence there is the need to guarantee its quality and eliminate any form of fakery or counterfeiting. Already there have been several reports cataloguing the distribution and use of counterfeit and substandard artesunate tablets in many South-East Asian countries ${ }^{6-}$

11. Many African countries lack the resources to employ advanced techniques such as high performance liquid chromatography; mass spectrometry and Raman spectroscopy ${ }^{12}$ which can be used to ascertain the authenticity of artemisinin products in the market and are therefore vulnerable to counterfeiting and substandard drugs. Also, artesunate and other artemisinins, being generally expensive drugs, are potential targets of counterfeiting. As a result of the above factors, Africa has been cited as the next possible destination for counterfeit and substandard artemisinins ${ }^{10}$. Already, cases of counterfeit and substandard artemisinins have been reported in African countries such as Tanzania, Cameroon ${ }^{8}$, Kenya and the Democratic Republic of Congo ${ }^{16}$.
In Ghana, artesunate tablet is the commonest artemisinin product in the market and is available in various strengths from both local and foreign manufacturers. The quality of these antimalarials if not properly safeguarded could lead to therapeutic failure in patients and the development of drug resistance. The objective of this study was, therefore, to evaluate the quality of artesunate tablets available in community and wholesale pharmacies in Kumasi, Ghana. The study also sought to determine the existence or otherwise of counterfeit or fake artesunate tablets in the study area.

\section{EXPERIMENTAL Materials}

Five blisterpacks each of 17 brands of artesunate tablets manufactured by various pharmaceutical companies in Ghana (5 brands) and abroad (12 brands) were purchased between February and March 2006 from different pharmacy shops located in Kumasi, Ghana (Table 1). The artesunate tablet brands include 4 combi-packs of artesunate and amodiaquine and one (1) combi-pack of artesunate and sulphamethoxypyrazine/pyrimethamine.

Artesunate powder was a gift from Kinapharma Ltd. (Kumasi, Ghana). All the artesunate tablet brands sampled had a remaining shelf life of at least one year at the time of sampling. Fast Red TR salt (1, 5Naphthalene-disulfonate salt, reagent grade) was obtained from Acros Organics (New Jersey, USA). Glacial acetic acid of density $1.048-1.051 \mathrm{~g} / \mathrm{ml}$ and sodium hydroxide were obtained from Philip Harris Plc. (Lichfield, England).

\section{Uniformity of weight and disintegration of tablets}

The uniformity of weight was determined as the relative standard deviation of twenty randomly selected artesunate tablets.

The disintegration times of six randomly selected tablets was determined in distilled water at $37 \pm 0.5{ }^{\circ} \mathrm{C}$ using an Erweka tablet disintegration tester (Type ZT3/1, Heusenstamm, Germany). 


\section{Breaking strength and friability of tablets}

The breaking strength of ten randomly selected tablets was determined using a Schleuniger hardness tester (Schleuniger and Co., Switzerland).

The friability (\%) of ten randomly selected tablets was determined using an Erweka friabilator (Erweka TA20, England) operated at $25 \mathrm{rpm}$ for 4 minutes.

\section{Qualitative test on artesunate tablets}

A test for the presence or absence of artesunate in the tablets, which was meant to distinguish genuine artesunate from counterfeit ones, was carried out using a colorimetric field method for the qualitative testing of artesunate in tablets (standard test) ${ }^{13}$.

\section{Assay of artesunate tablets}

Artesunate tablets were quantitatively analysed using a previously described and validated colorimetric method with minor modifications ${ }^{1}$. A number of artesunate tablets (2-5, depending on artesunate brand) were crushed into powder in a porcelain mortar with a pestle. Artesunate powder equivalent to 0.1 $\mathrm{g}$ artesunate was weighed into a $100 \mathrm{ml}$ volumetric flask. A quantity of $1 \mathrm{M}$ sodium hydroxide was added to the artesunate powder to the $40 \mathrm{ml}$ mark and allowed to stand for $20 \mathrm{~min}$ to hydrolyse the drug. The sample was filtered with a sintered glass filter into a $100 \mathrm{ml}$ volumetric flask and to the filtrate was added $40 \mathrm{ml}$ of $1.1 \mathrm{M}$ acetic acid, followed by $20 \mathrm{ml}$ of $5 \mathrm{mg} / \mathrm{ml}$ Fast Red TR. The resultant solution was allowed to stand for $5 \mathrm{~min}$ to form a yellowish solution. The amount of artesunate in the final solutions formed were assayed spectrophotometrically (Cecil 8000 Series, Cecil Instruments, Cambridge, England) at $420 \mathrm{~nm}$ with the use of regression data obtained from a calibration plot of artesunate powder $\left(r^{2}=0.9941\right)$. The tests were repeated twice and the results presented are the mean of three determinations. The whole procedure was repeated for the different brands of artesunate tablets.

\section{RESULTS}

The shelf life of the artesunate tablets ranged from 2 to 4 years. Table 1 shows the country of manufacture and the mechanical properties of the artesunate tablets. The country of manufacture was indicated for all the samples, except for ART 1. The percentage weight deviation of the various brands of artesunate from their respective mean weights was less than $10 \%$. The mean tablet weight for $25 \mathrm{mg}$, $50 \mathrm{mg}, 100 \mathrm{mg}$ and $200 \mathrm{mg}$ strength artesunate brands was $203.5 \pm 7.45 \mathrm{mg}$ ( $\mathrm{n}$ $=1), 287.1 \pm 57.2 \mathrm{mg}(\mathrm{n}=11), 309.9 \pm 83.6$ $\mathrm{mg}(\mathrm{n}=4)$ and $566.2 \pm 9.05 \mathrm{mg}(\mathrm{n}=1)$, respectively. The breaking strength of the tablets ranged from $2.5-17.2 \mathrm{~kg} / \mathrm{cm}^{2}$. Only ART 13 and ART 15 had breaking strength values lower than $4.0 \mathrm{~kg} / \mathrm{cm}^{2}$. The percentage friability was lower than $1 \% \mathrm{w} / \mathrm{w}$ (range: $0.04-$ $0.85 \% \mathrm{w} / \mathrm{w}$ ) for all the tablets tested. All the tablets disintegrated in aqueous medium in less than 5 minutes (range: $41 \pm 1.82-257 \pm$ $13.5 \mathrm{~s})$.

Qualitative tests on all the different brands of artesunate tablets resulted in the formation of a yellowish product of varying colour intensity. Table 2 depicts the content of artesunate in the tablets. The percentage artesunate content ranged from 47.9 to $99.9 \%$. Six $(35.3$ $\%$ ) of the tablets had artesunate content $\geq 90$ $\%$ while eleven $(64.7 \%)$ had artesunate content $<90 \%$ of the label claim. On the other hand, three (17.6\%) of the samples had artesunate content $\geq 95 \%$ while fourteen $(82.4 \%)$ was $<95 \%$.

\section{DISCUSSION}

The country of manufacture was indicated on the packaging of all the brands of artesunate tablets except for ART 1 where the only address given was that of the dealer/marketing agent in the United Kingdom. This observation makes ART 1 a product of doubtful quality. All the tablets sampled were within their shelf life at the time of the study. Physical examination of the product packaging and the artesunate tablets of the other brands did not give any indication of fakery or counterfeiting. Qualitative tests on the artesunate tablets using the Fast Red TR 
Table 1: The country of manufacture and some mechanical properties of artesunate tablets

\begin{tabular}{|c|c|c|c|c|c|}
\hline Sample code & $\begin{array}{l}\text { Country of } \\
\text { Manufacture }\end{array}$ & $\begin{array}{l}\text { Mean } \\
\text { tablet } \\
\text { weight (mg) }\end{array}$ & $\begin{array}{l}\text { Breaking } \\
\text { strength } \\
\left(\mathbf{k g} / \mathrm{cm}^{2}\right)\end{array}$ & $\begin{array}{c}\text { Friability } \\
\text { (\%) }\end{array}$ & $\begin{array}{c}\text { Disintegration } \\
\text { time (s) }\end{array}$ \\
\hline ART 1 & $\mathrm{NI}$ & $318.8 \pm 9.94$ & $12.8 \pm 2.11$ & 0.04 & $193 \pm 9.4$ \\
\hline ART 2 & India & $282.3 \pm 3.17$ & $17.2 \pm 3.10$ & 0.07 & $156 \pm 12.9$ \\
\hline ART 3 & China & $272.3 \pm 2.13$ & $5.3 \pm 0.58$ & 0.31 & $56 \pm 6.4$ \\
\hline ART 4 & China & $288.4 \pm 5.41$ & $12.1 \pm 1.00$ & 0.15 & $68 \pm 4.7$ \\
\hline ART 5 & Ghana & $283.2 \pm 6.09$ & $7.3 \pm 1.25$ & 0.24 & $87 \pm 3.6$ \\
\hline ART 6 & India & $343.3 \pm 4.55$ & $13.7 \pm 0.61$ & 0.08 & $173 \pm 8.2$ \\
\hline ART 7 & Ghana & $283.2 \pm 7.06$ & $5.5 \pm 0.77$ & 0.22 & $139 \pm 4.9$ \\
\hline ART 8 & India & $294.8 \pm 3.28$ & $5.6 \pm 1.35$ & 0.20 & $77 \pm 3.6$ \\
\hline ART 9 & Belgium & $379.0 \pm 3.55$ & $14.9 \pm 3.07$ & 0.01 & $148 \pm 13.4$ \\
\hline ART 10 & Switzerland & $566.2 \pm 9.05$ & $17.1 \pm 2.51$ & 0.08 & $132 \pm 12.7$ \\
\hline ART 11 & Ghana & $397.1 \pm 8.01$ & $7.2 \pm 0.53$ & 0.85 & $61 \pm 10.6$ \\
\hline ART 12 & India & $202.5 \pm 5.50$ & $4.7 \pm 0.59$ & 0.41 & $121 \pm 23.9$ \\
\hline ART 13 & India & $192.5 \pm 8.30$ & $3.4 \pm 0.56$ & 0.52 & $44 \pm 2.3$ \\
\hline ART 14 & Belgium & $372.5 \pm 8.51$ & $6.6 \pm 1.28$ & 0.44 & $41 \pm 1.82$ \\
\hline ART 15 & Ghana & $203.5 \pm 7.45$ & $2.5 \pm 0.43$ & 0.84 & $58 \pm 4.1$ \\
\hline ART 16 & Ghana & $286.5 \pm 9.60$ & $4.5 \pm 0.39$ & 0.57 & $90 \pm 27.4$ \\
\hline ART 17 & India & $201.5 \pm 8.50$ & $5.0 \pm 0.43$ & 0.83 & $257 \pm 13.5$ \\
\hline
\end{tabular}

dye technique also produced yellowish coloured products signifying the presence of artesunate in all the artesunate tablet brands. Thus, none of the tablets tested was found to be counterfeit. Counterfeit drugs have been defined by the WHO as drugs which are 'deliberately and fraudulently mislabelled with respect to identity or source and occur with branded and generic products and may include products with the correct ingredients but fake packaging, with the wrong ingredients, without active ingredients or with insufficient active ingredients ${ }^{14}$. Variation in colour intensity of the samples indicates a variation in the amount of artesunate contained in the different brands of artesunate tablets, signifying the possibility of substandard tablets. Substandard drugs have been defined as medicines that have been manufactured below established standards of quality ${ }^{14}$.

Most of the tablets possessed appropriate mechanical properties in terms of weight uniformity, breaking strength, friability and disintegration time (Table 1). The different brands of artesunate tablets showed acceptable weight uniformity with weight deviations less than $10 \% \mathrm{w} / \mathrm{w}$. The breaking strength of the tablets was $\geq 4 \mathrm{~kg} / \mathrm{cm}^{2}$ except for ART $13\left(3.4 \mathrm{~kg} / \mathrm{cm}^{2}\right)$ and ART $15(2.5$ $\mathrm{kg} / \mathrm{cm}^{2}$ ). Thus, ART 13 and ART 15 failed the breaking strength test. The breaking strength is used to characterise the hardness of tablets. Tablets with breaking strength values $\geq 4 \mathrm{~kg} / \mathrm{cm}^{2}$ have acceptable hardness. The friability of all the artesunate brands was $<1 \%$ $\mathrm{w} / \mathrm{w}$ and the disintegration times were less than 15 minutes, thus all the artesunate brands passed the friability and disintegration tests. It could thus be inferred that all the artesunate brands studied could withstand abrasion without loss of tablet integrity and could disintegrate readily in aqueous medium, especially in the gastrointestinal tract.

Quantitative analysis using absorbance measurements showed $6(35.3 \%)$ of the tablets passing and $11(64.7 \%)$ failing the WHO International Pharmacopoeia requirement which specifies artesunate tablets to contain not less than $90.0 \%$ and not more than $110.0 \%$ of the amount of artesunate indicated on the label ${ }^{15}$. On the other hand, only $3(17.6 \%)$ of the samples passed the European Pharmacopoeia content specifications of $95-105 \%$ of the active drug substance $^{17}$ while $14(82.4 \%)$ did not meet 
Table 2: The strength and content of artesunate in different brands of artesunate tablets sampled (mean of 3 measurements)

\begin{tabular}{|c|c|c|c|c|c|}
\hline $\begin{array}{l}\text { Sample } \\
\text { code }\end{array}$ & $\begin{array}{l}\text { Active ingredients per } \\
\text { Brand }\end{array}$ & $\begin{array}{l}\text { Artesunate } \\
\text { content (mg) }\end{array}$ & $\begin{array}{l}\text { Artesunate } \\
\text { content (\%) }\end{array}$ & $\begin{array}{l}\text { Content } \\
\text { requiren } \\
\text { Ph. Int. }\end{array}$ & $\begin{array}{l}\text { uniformity } \\
\text { nents } \\
\text { Ph. Eur }\end{array}$ \\
\hline ART 1 & Artesunate, $50 \mathrm{mg}$ & 35.76 & 71.52 & Fail & Fail \\
\hline ART 2 & Artesunate, $50 \mathrm{mg}$ & 44.35 & 88.70 & Fail & Fail \\
\hline ART 3 & Artesunate, $50 \mathrm{mg}$ & 32.46 & 64.91 & Fail & Fail \\
\hline ART 4 & Artesunate, $50 \mathrm{mg}$ & 38.66 & 77.31 & Fail & Fail \\
\hline ART 5 & Artesunate, $50 \mathrm{mg}$ & 46.86 & 93.72 & Pass & Fail \\
\hline ART 6 & Artesunate, $50 \mathrm{mg}$ & 26.58 & 53.16 & Fail & Fail \\
\hline ART 7 & Artesunate, $50 \mathrm{mg}$ & 47.12 & 94.24 & Pass & Fail \\
\hline ART 8 & Artesunate, $50 \mathrm{mg}$ & 36.01 & 72.02 & Fail & Fail \\
\hline ART 9 & Artesunate, $100 \mathrm{mg}$ & 99.93 & 99.93 & Pass & Pass \\
\hline ART 10 & Artesunate, $200 \mathrm{mg}$ & 199.66 & 99.83 & Pass & Pass \\
\hline ART 11 & Artesunate, $50 \mathrm{mg}$ & 32.25 & 64.50 & Fail & Fail \\
\hline ART 12 & Artesunate, $50 \mathrm{mg}$ & 44.13 & 88.25 & Fail & Fail \\
\hline ART $13^{*}$ & $\begin{array}{l}\text { Artesunate, } 50 \mathrm{mg} \\
\text { Amodiaquine, } 153.1 \mathrm{mg}\end{array}$ & 23.95 & 47.90 & Fail & Fail \\
\hline ART 14* & $\begin{array}{l}\text { Artesunate, } 100 \mathrm{mg} \\
\text { Sulfamethoxypyrazine, } \\
250 \mathrm{mg} / \text { Pyrimethamine, } \\
12.5 \mathrm{mg}\end{array}$ & 93.73 & 93.73 & Pass & Fail \\
\hline ART 15* & $\begin{array}{l}\text { Artesunate, } 25 \mathrm{mg} \\
\text { Amodiaquine, } 75 \mathrm{mg}\end{array}$ & 21.91 & 87.65 & Fail & Fail \\
\hline ART 16* & $\begin{array}{l}\text { Artesunate, } 100 \mathrm{mg} \\
\text { Amodiaquine, } 300 \mathrm{mg}\end{array}$ & 97.18 & 97.18 & Pass & Pass \\
\hline ART $17^{*}$ & $\begin{array}{l}\text { Artesunate, } 100 \mathrm{mg} \\
\text { Amodiaquine, } 300 \mathrm{mg}\end{array}$ & 89.38 & 89.38 & Fail & Fail \\
\hline
\end{tabular}

the requirement. All the samples that failed the International Pharmacopoeia (90-110\%) or the European Pharmacopoeia (95-105\%) content requirements of artesunate were underdosed and hence were substandard. For instance, the two most underdosed artesunate samples, namely: ART 6 and ART 13 contained a little over half $(53.14 \%)$ and less than half $(47.90 \%)$ of the labelled amount of the drug, respectively. On the whole, artesunate tablets manufactured in Europe were of higher quality than those produced in India, China, or Ghana.

Even though no counterfeit artesunate tablets was observed in the study a greater proportion of the brands sampled were found to be of substandard quality. The use of such substandard artesunate tablets in treatment 
would result in sub-therapeutic levels of the drug in patients, leading to treatment failure and possible development of drug resistance. There is, therefore, the need for drug regulatory bodies in Ghana and other African countries to be vigilant and undertake routine assessment of the quality of artesunate and other artemisinin products on the market in order to flush out counterfeit and substandard ones.

\section{CONCLUSION}

No counterfeit or fake artesunate was found out of 17 brands of artesunate tablets sampled. Eleven of the samples were however found to be of substandard quality as they contained lower amounts of artesunate. Routine tests using the fast-red TR test (dye test) is invaluable in detecting counterfeit and substandard artesunate tablets on the market.

\section{ACKNOWLEDGEMENT}

The authors acknowledge Kinapharma Ltd., Accra, Ghana for the kind donation of pure artesunate powder used for the study.

\section{REFERENCES}

1. Green $M D$, Mount $D L$, Wirtz RA, White NJ. A colorimetric field method to assess the authenticity of drugs sold as the antimalarial artesunate. J Pharm Biomed Anal 2000; 24: 6570.

2. Ministry of Health, Ghana National Drugs Programme. Standard Treatment Guidelines, $5^{\text {th }}$ Ed. 2004; pp 371-377.

3. Woodrow CJ, Haynes RK, Krishna S. Artemisinins. Postgrad Med J 2005; 81: 71-78.

4. Schwarz NG, Oyakhirome S, Pötschke M, Gläser B, Klouwenberg PK, Altun H, Adegnika AA, Issifou S, Kun JFJ, Kremsner PG, Groubusch MP. 5Day nonobserved artesunate monotherapy for treating uncomplicated falciparum malaria in young Gabonese children. Am J Trop Med Hyg 2005; 73(4): 705-709.

5. Borrmann S, Adegnika AA, Missinou MA, Binder RK, Issifou S, Schindler A, Matsiegui $P$, Kun JFJ, Krishna S, Lell B, Kremsner PG. Short-course artesunate treatment of uncomplicated Plasmodium falciparum malaria in Gabon. Antimicrob Agents Chemother 2003; 47(3): 901-904.

6. Hall KA, Newton $P N$, Green $M D$, De Veij $M$, Vnadenabeele $P$, Pizzanelli $D$, Mayxay $M$, Dondorp A, Fernandez FM. Characterization of counterfeit artesunate antimalarial tablets from
Southeast Asia. Am J Trop Med Hyg 2006; 75(5): 804-811.

7. Newton $P$, Proux $S$, Green $M$, Smithuis $F$, Rozendaal J, Prakongpan S, Chotivanich K, Mayxay M, Looareesuwan S, Farrar J, Nosten F, White NJ. Fake artesunate in Southeast Asia. Lancet 2001; 357:1948-1950.

8. Rozendaal J. Fake antimalaria drugs in Cambodia. Lancet 2001; 357: 890.

9. Newton PN, Dondorp A, Green M, Mayxay M, White NJ. Counterfeit artesunate antimalarials in Southeast Asia. Lancet 2003; 362:169.

10. Newton PN, McGready R, Fernandez F, Green MD, Sunjio $M$, Bruneton $C$, Phanouvong $S$, Millet $P$, Whitty CJ, Talisuna AO, Proux S, Christophel $E M$, Malenga $G$, Singhasivanon $P$, Bojang $K$, Kaur H, Palmer K, Day NP, Greenwood BM, Nosten F, White NJ. Manslaughter by fake artesunate in Asia - Will Africa be next? PLoS Med 2006; 3:e197.

11. Dondorp AM, Newton PN, Mayxay M, Van Damme W, Smithuis FM, Yeung S, Petit A, Lynam AJ, Johnson A, Hien TT, McGready R, Farrar JJ, Looareesuwan S, Day NPJ, Green MD, White NJ. Fake antimalarials in Southeast Asia are a major impediment to malaria control: Multinational cross-sectional survey on the prevalence of fake antimalarials. Trop Med Int Health 2004; 9:124-126.

12. De Veij $M$, Vandenabeele $P$, Hall KA, Fernandez $F M$, Green $M D$, White NJ, Dondorp AM, Newton PN, Moens L. Fast detection and identification of counterfeit antimalarial tablets by Raman spectroscopy. J Raman Spect 2006; 38: 181-187.

13. Pan American Health Organisation. A field method for the assay of artesunate in tablets. Available from:

http://www.paho.org/english/ad/dpc/cd/malfake-artesunate-who.htm (accessed 20 November 2007)

14. World Health Organisation Fact sheet $N^{0} 275$. Counterfeit medicines. Revised 14 November 2006. Available from: http://www.who.int/mediacentre/factsheet/fs275 len/ (accessed 17 October 2007).

15. The International Pharmacopoeia; $4^{\text {th }}$ Edition. World Health Organization, Geneva, 2006.

16. Atemnkeng AA, De Cock K, Plaizier-Vercammen J. Quality control of active ingredients in artemisinin-derivative antimalarials within Kenya and DR Congo. Trop Med Int Health 2007; 12: 68-74.

17. European Pharmacopoeia IV. Published by the European Directorate for the Quality of Medicines for the Council of Europe, 2003. Strasbourg CEDEXI, France. 